This is a so-called personal version (author's manuscript as accepted for publishing after the review process but prior to final layout and copyediting) of the article:

Ketokivi, Mikko \& Mantere, Saku. Two Strategies for Inductive Reasoning in Organizational Research. Academy of Management Review, 2010, 35: 315-333.

Researchers are kindly asked to use the official publication in references.

\title{
TWO STRATEGIES FOR INDUCTIVE REASONING IN ORGANIZATIONAL
}

\section{RESEARCH}

\author{
Mikko Ketokivi \\ Aalto University and University of Lausanne \\ mikko@ketokivi.fi
}

\begin{abstract}
Saku Mantere
Hanken School of Economics and Rouen Business School saku.mantere@hanken.fi
\end{abstract}

We would like to thank Editor Martin Kilduff and the reviewers for helpful comments and suggestions. We are also indebted to Teppo Felin, Mike Manning, Bill McKelvey, Thomas Powell, Fabrizio Salvador, John Sillince, Eero Vaara, and research seminar participants at HEC School of Management (Paris) and HEC Lausanne for comments on earlier drafts of the paper. 
TWO STRATEGIES FOR INDUCTIVE REASONING IN ORGANIZATIONAL

RESEARCH

\begin{abstract}
Incompleteness of inductive reasoning presents an enduring dilemma to organizational research. We examine two practical reasoning strategies—idealization and contextualization — that can be used at the pinnacle of this dilemma: when theoretical conclusions are drawn from empirical data. Understanding the two strategies can lead to more effective argumentation and evaluation. Appreciating the methodological incompleteness of both strategies in turn helps us distinguish between the methodological and the policy dimensions of organization-scientific debates.
\end{abstract}




\section{INTRODUCTION}

One of the main challenges for an empirical organization scientist is the drawing of theoretical conclusions from empirical data in a manner that is credible and understandable to one's audience. This often constitutes not only a necessary condition (e.g., Daft, 1995; Kilduff, 2007), but also one of the central challenges in the acceptance of an argument (e.g., Locke \& GoldenBiddle, 1997). Convincing an audience of the credibility of one's claims is challenging, the most visible manifestation of which is the unpredictability we experience in the evaluation processes of organization-scientific manuscripts (Starbuck, 2006). Various potential drivers of this unpredictability have been identified: theoretical and paradigmatic proliferation (Pfeffer, 1993; Van Maanen, 1995), the difficulties in positioning one’s argument vis-à-vis a broader theoretical discourse and demonstrating contribution (Locke \& Golden-Biddle, 1997), epistemological incommensurability (McKelvey, 1997; Moldoveanu \& Baum, 2002), the lack of standards for qualitative research in particular (Pratt, 2008), and the sheer complexity of the social negotiation process (Astley, 1985). Acknowledging these extant views on the challenge, we focus in this paper on a philosophical puzzle that presents an enduring dilemma for all empirical organization science: the incompleteness of inductive reasoning (Hume, 1969, 1739-1740 original). All claims that are based on empirical data have at their foundation some variant of inductive reasoning, but the justification of inductive arguments constitutes an unresolved issue in contemporary epistemology. The debate on induction has been ongoing throughout the history of Western philosophy and for all we know, may never lead to a solution (Lipton, 2004; Nagel, 1965). We examine strategies for addressing the incompleteness of inductive reasoning and their implications to the construction and evaluation of arguments. 


\section{INDUCTIVE REASONING AND THE PRACTICAL REASONING DILEMMA}

Incompleteness of induction presents organization scientists with a practical reasoning dilemma. Practical reasoning refers to the social process by which we in our scientific texts proceed from various grounds to various claims in an attempt to convince an audience (Toulmin, 2003). In framing the challenge as a dilemma, we in turn acknowledge that there are no universally accepted and sound principles to govern the practical reasoning process. The resulting uncertainty in the evaluation process arises not from complexity but from incompleteness and consequently, uncertainty cannot be eliminated by making complexity tractable (e.g., McGrath, Martin, \& Kulka, 1982). Instead, authors must negotiate with their audiences by invoking alternative reasoning strategies. A journal manuscript review process is a prime example of such negotiation.

Understanding the dilemma is important for a number of reasons. We sometimes have a tendency to dismiss arguments by pointing to their weaknesses, not acknowledging — perhaps not even understanding —-their strengths (e.g., Elbow, 1973; Van Maanen, 1995). In these dismissals, the focus of critique is often not so much on ontological or epistemological concerns as it is specifically on how theoretical conclusions are drawn from empirical data (Daft, 1995; Pratt, 2008). Disagreement and confusion over how theoretical conclusions are drawn from data are by no means limited to debates between research traditions (e.g., qualitative vs. quantitative), they are prevalent within paradigms and theoretical discourses as well (e.g., Carter \& Hodgson, 2006; Daft, 1995). Therefore, we do not find it meaningful to frame the dilemma as epistemologically (Moldoveanu \& Baum, 2002) or theoretically (Pfeffer, 1993) based. Instead, we introduce a new level of analysis to examining organization-scientific discourse: reasoning from grounds to claims (e.g., Toulmin, 2003). Understanding the logic of different reasoning strategies can help 
authors on the one hand build consistency and transparency into how they seek justification. On the other hand, it can also help reviewers develop a broader skill base in evaluating arguments and most importantly, recognize which parts of their critique are methodological and which are based on policy. Taken together, acknowledging the dilemma and the incompleteness of reasoning leads to a more constructive dialogue between authors and their audience.

\section{What is the dilemma?}

Reasoning has conventionally been divided into two distinct categories, deduction and induction (e.g., Frigg \& Hartmann, 2006, see also the Appendix for more details). In deduction, one proceeds from a set of general premises to a more specific conclusion, with the strict condition that the conclusion must follow analytically from the premises; the normative rule for reasoning is logical coherence. Inductive reasoning in contrast runs in the opposite direction: from particulars to generalizations. When we generalize from data, our inferences are always inductive. Unlike deduction, inductive conclusions contain knowledge claims not analytically implied by the premises, which is why induction is sometimes dubbed an ampliative form of reasoning (e.g., Salmon, 1966): it “amplifies” our knowledge in that the conclusion is more than a restatement of the premises.

The problem of induction is one of the famous and enduring puzzles in the philosophy of science (Hume, 1969). We are only able to observe particular events, not generalities, and all events we observe are past occurrences. This fact shakes the foundation of two important goals of an empirical science: generalization and prediction. Because of the problem of induction, our practices of generalizing and predicting are unavoidably habitual not epistemic. Hume (1969: 189) crystallized his crowning achievement: "there is nothing in any object, consider'd in itself, 
which can afford us a reason for drawing a conclusion beyond it; and that even after the observation of the frequent or constant conjunction of objects, we have no reason to draw any inference concerning any object beyond those of which we have had experience.” Inductive inference lacks the solid normative foundation of deduction and is thus methodologically incomplete (Hume, 1969; Nagel, 1965). The problem of induction applies in all situations where a generalization is made using inductive reasoning.

The problem of induction is not merely a topic of philosophical inquiry, it implies a relevant and ubiquitous challenge for all empirical research. Due to the unavoidable logical gap between empirical data and theoretical generalizations, any given set of data can be used to formulate multiple generalizations, all of which are coherent with the data (Goodman, 1954; Maher, 1998). The resulting dilemma the empirical scientist faces is the following: given that several alternative theoretical generalizations are logically coherent with my data and my primary form of reasoning, induction, does not provide the logical means unambiguously to select one over the others, how do I convince my audience of the choices I make?

The debate over the selection of theoretical explanations is linked to the epistemic virtues of empirical science (Lycan, 1988). Should pragmatic virtues such as interestingness, usefulness, simplicity or conservativeness be applied when competing explanations are weighed? Some philosophers have argued that the potential of a theoretical explanation to answer open questions or create new ones-interestingness — is in fact a key consideration in the very justification of inductive arguments (Lipton, 2004; Quine \& Ullian, 1970; Sellars, 1956). Others, most notably van Fraassen (1980), have in contrast maintained that pragmatic virtues must not be invoked in weighing the soundness of inference. We arrive at one of the central topics of inquiry in contemporary philosophy of science: inductive inference (the steps we take to generalize our 
empirical findings) and theoretical explanation (the steps we take to formulate the findings in a theoretical language) are conceptually separate, but the extent to which they are in principle separable and de facto separated in scientific practice is subject to debate (Lipton, 2004). The explanationist view acknowledges the use of pragmatic virtues in reasoning and embraces the idea that theoretical explanation indeed plays a role in scientific inference. The opposite, Spartan view, rejects pragmatic virtues and accepts truth as the only virtue in scientific inference (see Lycan, 1998, for a discussion of the two views).

\section{Practical reasoning, inference and explanation}

The assessment of scientific claims is a complex social process (Astley, 1985; Locke \& GoldenBiddle, 1997). Our focus in this paper is on those aspects of this negotiation process where authors engage in scientific reasoning and where their reasoning is evaluated. Toulmin's (2003) work on practical reasoning provides a useful conceptual basis. Toulmin viewed reasoning as a social process that takes place in dialogue between members of a scientific community, as opposed to being an intra-individual cognitive activity. Figure 1 summarizes Toulmin's model for reasoning, applied to our goal of examining how theoretical claims are made based on empirical grounds (see also Toulmin, 2003: 87-134). In Toulmin’s terminology, grounds constitute the premises of the argument: data, observations, or theoretical premises. Claims in turn can be theoretical interpretations or empirical and theoretical generalizations. Grounds and claims appear throughout scientific texts. Finally, warrants provide the justification for bridging the grounds with the claims; warrants are the "practical standards of argument” (Toulmin, 2003: 91) that are used to justify the claims from the grounds. 


\section{Insert Figure 1 about here}

Toulmin’s framework illuminates the important distinction between inference and explanation. When grounds are empirical data and claims theoretical conclusions, we can think of claims as explanations. Inference in turn is the mechanism that bridges the grounds with the claims; warrants are the essence of inference. In order to convince a scientific audience, authors have to defend both the inference and explanation associated with their arguments. There are two important aspects to understand about this process. First, inference that leads from empirical data to theoretical explanation is always based on inductive reasoning, which makes bridging the grounds with the claims subject to the problem of induction and therefore, methodologically incomplete. This is an alternative way of defining the reasoning dilemma in terms of research practice. Second, whether inference and explanation are treated as separate or as a single entity presents the author of an argument with an important challenge and choice opportunity, because there are no normative methodological guidelines for making the choice.

To be sure, grounds can be bridged to claims deductively as well, common in research based on mathematical modeling. These deductive practices are methodologically complete and therefore, not subject to the problem of induction. While we do not in any way wish to downplay the role of deductive reasoning and mathematical modeling in organizational research, we focus in this paper on warrant-seeking in empirical research, where inference is based on methodologically incomplete inductive reasoning. 


\section{Relevance of the dilemma to organization science: three examples}

Consider first a decision situation in which a quantitative researcher is contemplating two alternative regression models: (1) a model that explains $30 \%$ of the variance of the dependent variable with only main effects of the predictor variables in the model; (2) a model that explains $35 \%$ of variance, but has both main effects and interaction terms in the model. Which model should the researcher choose? The classical epistemic virtue of empirical adequacy (term coined by van Fraassen, 1980) — the ability of the model to produce predictions of the unknown — would side with the second model: the model that explains more variance is empirically more adequate. If in turn simplicity and parsimony constitute the criteria, one might argue that predicting $30 \%$ with a simple model has in a sense more explanatory value than predicting 35\% with a more complex one. There are no methodological normative guidelines to settle the score: the decision ultimately depends on which epistemic virtues the researcher selects and whether this selection is understood and accepted by the audience. Whether the pragmatic or the epistemic virtue is preferred in this example depends on the discourse in which the researcher wishes to participate. Simple explanations might be accepted in early contributions to a discourse; elaboration and improved empirical adequacy might be favored in more mature discourses.

Consider next researchers who derive hypotheses from theory and test them with data. These researchers are building one way or another on Whewell's (1840) and in particular, Hempel's (1965) formulation of the hypothetico-deductive (HD) method. In applying HD, the researcher in effect sidesteps the question of alternative explanations and focuses instead on testing a single theory for empirical adequacy. If the theory produces acceptable predictions of the unknown, such as the correct signs of regression coefficients or a significant portion of the variance of the dependent variable, the theory is deemed empirically adequate. If the theory is empirically 
adequate—-fits the data”-, the researcher typically will not entertain alternative explanations (e.g., Carter \& Hodgson, 2006). It is only in situations in which a theory does not exhibit empirical adequacy that alternative explanations are invoked.

Application of HD in organization science is problematic in situations where justification of alternative theoretical explanations is important. Nowhere are these problems more evident than in examinations of organizational boundaries (e.g., Santos \& Eisenhardt, 2005). Carter and Hodgson (2006), for instance, argued that many empirical studies that are pegged as empirical evidence for Williamson's (e.g., 1985) formulation of transaction cost economics (TCE) can be reinterpreted from other, competing organization-theoretic perspectives, some of which are incommensurate with TCE. Carter and Hodgson have thus questioned the way by which TCE theorists have drawn theoretical explanations from their inferences: while empirical adequacy may be sufficient for the acceptance of an inference, researchers invariably exhibit bias by crediting one theoretical explanation out of many potential ones. This challenge is a direct consequence of the problem of induction: $\mathrm{HD}$ as a research design may be useful as an inference tool, but it does not provide selection criteria for choosing between alternative explanations. If two incommensurate theories are both empirically adequate, how does one choose? HD does not provide the criterion for choice, because it is "overpermissive" in a rather disturbing way. In his famous critique, Salmon (1971) showed that a man taking his wife's birth-control pills is from the point of view of HD logic a perfectly acceptable explanation for why the man does not become pregnant. This admittedly silly but analytically valid example shows that the HD method provides no insurance against accepting not just inferior but indeed theoretically absurd explanations. In light of this serious handicap, how could HD possibly be used to select between two or more alternative explanations? It cannot. 
Consider finally one of the enduring debates in organization science: the role of the researcher as an active reasoner (e.g., Deetz, 1996). Debate over the role of the researcher was the primary source of disagreement between Glaser and Strauss, the two architects of one of the most established methods of qualitative inquiry, grounded theory (Glaser \& Strauss, 1967). According to Locke (1996: 241), Glaser and Strauss strongly disagreed in their later writings on researchers' relationship to their data: “Strauss and Corbin’s (1990) rewriting expresses a very active, even provocative, role in which researchers essentially interrogate the data they gather to arrive at conceptual categories... Glaser not only finds such active provocation of the data unnecessary but also objects to it on the basis that it will contaminate the concepts that are formed.” Strauss (1987; Strauss \& Corbin, 1990) highlighted the role of the researcher as an “interrogator of the data," whereas Glaser (1992) wanted to separate inference from explanation: what the researcher finds interesting must not interfere with the interpretation of data.

The debate over the role of the researcher can be traced to the problem of induction as well. If the problem of induction were solved—if we had at our disposal a logic of induction that leads us unequivocally from observations to theoretical explanation—, we could as researchers abstract away our own involvement from the act of reasoning. In the absence of a universal logic for justifying one explanation over others, classical forms of induction (see the Appendix) provide neither a normative framework for researchers nor a fair account of what happens in the process of constructing of theoretical explanations from data (Harman, 1965; Niiniluoto, 1999). These shortcomings have inspired the development of new, more descriptive formulations of induction that admit to the idea of an active reasoner. The most influential of these is the inference to the best explanation (IBE). Inference to an explanation, sometimes labeled abductive reasoning (Niiniluoto, 1999; Peirce, 1878), focuses on the descriptive rather than the normative 
aspects of scientific reasoning. According to IBE, it is always the researcher who selects the "best” among competing explanations and the de facto criteria for "best" are defined by pragmatic virtues such as interestingness, usefulness, simplicity or conservativeness, not truth value or even empirical adequacy. This effectively makes inference and theoretical explanation integral parts of a single process (Harman, 1965; Lipton, 2004). Choice of virtues is not, however, given to the researcher, it is instead often determined by the theoretical discourse or the paradigm in which the arguments are presented. In this sense, reasoning is not subjective in the conventional meaning of the word. Some research approaches and discourses, for instance, promote simplicity more than others (e.g., Langley, 1999). IBE as a form of reasoning originated in scientific realist philosophy (Harman, 1965), but is not limited to realism. Indeed, many constructivists (e.g., Locke, Golden-Biddle, \& Feldman, 2008; Wodak, 2004) rely on abduction, the historical precursor of IBE (see the Appendix).

The main strength of IBE is that it is a candid description of how empirical scientists in practice make choices in their reasoning. It thus overcomes some of the problems associated HD, which does not provide us with any understanding on how we choose—or should choose—-between alternative explanations. To be sure, IBE is not a universal solution to the problem of induction, because it runs counter to the classical epistemic values of objectivity and truth. Critics of IBE have argued that the interestingness of an explanation is a pragmatic not an epistemic virtue and as such unacceptable (Lycan, 1998; van Fraassen, 1980). If we allow our sense of what would be an interesting explanation to affect our inferences, what stops us from retrofitting our data to fit the explanation that we prefer? After all, in his famous refutation of logical positivism, Quine (1951: 40) argued that any explanation can be retrofitted to an observation by making a sufficient number of adjustments. Proponents of IBE have responded that IBE is not a normative but 
descriptive account of inductive practice and an accurate one to boot. They have also pointed out that normative methodology tends to build on idealizations that provide little guidance to and understanding of research practice (Lipton, 2004). Architects of two principal normative methods, HD (Hempel, 1965) and deductive theory-testing (Popper, 1959), both acknowledged this as well (Hempel, 1965: 412; Popper, 1959: 31-32).

The debate over IBE remains unfinished. In his conclusion to perhaps the most celebrated recent contribution, Lipton (2004: 210) noted that "[while] this book has only scratched the surface of our inductive practices, ... I take some comfort in the otherwise discouraging fact that an account of our inductive practices does not have to be very good to be the best we now have.” This serious incompleteness may be the most important source of the prevailing uncertainty we experience in organizational research: if we have only a poor understanding of inductive practice, how can, for instance, multiple referees evaluate a manuscript with consistency?

In summary, we cannot call upon a philosophy of science (a) to regulate which virtues should be preferred in choosing between alternative regression models; (b) to declare either Glaser or Strauss the winner in the debate over the role of the researcher in grounded theory research; or (c) to provide a methodologically solid alternative to the HD method (or any other normative methodological reconstruction) that does not exhibit the weaknesses of IBE. In the absence of an explicit logic of induction to guide the justification of claims, we present two practical reasoning strategies available to organization scientists: (1) the idealization strategy, where inference and explanation are treated as separate activities, and (2) the contextualization strategy, where the two are treated as one. There is no holy grail: empirical scientists have to choose between the strategies or try to forge an uneasy alliance between them. The choice may, however, have farreaching implications when we seek to convince an audience. Using contextualization when the 
audience expects idealization, or vice versa, can easily lead to confusion and rejection of an argument. Both strategies have their counterparts in the philosophy of science literature: idealization is based on idealized inter-subjective reasoning such as HD and mechanistic forms of induction (see the Appendix); contextualization in turn is based on IBE. Both strategies are applicable in both qualitative and quantitative research.

\section{IDEALIZATION AND CONTEXTUALIZATION AS PRACTICAL REASONING STRATEGIES}

Some researchers reject pragmatic virtues and seek backing for their inference before engaging in explanation (e.g., most HD studies); others choose not to engage in inference without simultaneously incorporating theoretical explanation (e.g., Alvesson \& Kärreman, 2008; Locke et al., 2008). Two alternative reasoning strategies emerge: idealization and contextualization. The two are indeed strategies in the sense that choosing between them involves a tradeoff between alternatives neither of which can be demonstrated to be superior to the other (see Langley, 1999; McGrath, 1982; Oliver, 1991, for similar use of the word "strategy”). Both strategies have their strengths and their weaknesses, just like any strategic choice has (Table 1). The tension between the two strategies can be traced to the debate between IBE and intersubjective forms of induction.

Insert Table 1 about here 


\section{Idealization}

Authors ranging from Husserl to Einstein have argued that idealization is one of the hallmarks of science (Ben-Menahem, 2001; McKelvey, 2002). Idealization conventionally understood involves the simplification of a complex phenomenon in an attempt to make it tractable (Frigg \& Hartmann, 2006). While idealization is often used to model the phenomenon under studyfrictionless planes, point masses or markets in equilibrium—, our focus is on the idealization of the practical reasoning process. The goal of idealization is to provide normative guidelines for justifying inductive arguments.

Idealization is based on the classical epistemic virtues of objectivity and truth; inference is evaluated as an autonomous process governed by normative, inter-subjective standards. In applying HD, perhaps the most commonly used normative reasoning standard in organization science, we expect the scientist to be able to draw statistical inferences from data using reasoning that is theory, context and researcher invariant: one does not test contingency theory and institutional theory with different sets of inference tools.

The practice of appealing to methodological idealizations in securing warrants is well established (Kaplan, 1964; Toulmin, 2003) and indeed, may be the most intuitive way of thinking about how scientists seek to convince one another. By invoking the HD idealization, for instance, authors seek the warrant to move from theoretical propositions to observational hypotheses by appeal to deductive reasoning. They will then later in the theoretical interpretation of evidence rely on this deduction: because the hypotheses were analytically derived from theory, the researcher is entitled to credit specifically the theory under scrutiny with empirical adequacy. 
Use of the idealization strategy is not limited to quantitative research or ontological realism. Ranging from Eisenhardt's (1989) eight-step reconstruction of the inductive case study design to Langley’s (1999) seven strategies of process research, qualitative researchers have provided reconstructions of scientific inference as well. Referencing these reconstructed logics (Kaplan, 1964) has the same goal as referencing HD: securing argument warrants by appeal to general methodological reasoning principles.

The actual epistemic virtue adopted in idealization is not truth but empirical adequacy, that is, the ability of the theory to produce empirical predictions (Carnap, 1950; van Fraassen, 1980). Qualitative researchers that embrace empirical adequacy in turn seek not prediction or statistical generalization but theories that are more likely to be "empirically valid" (Eisenhardt, 1989: 532). To clarify, theories cannot be expected to make predictions about the future-an unenforceable criterion—, but they are expected to predict the unknown. To the extent that theories make satisfactory predictions of the unknown, they are empirically adequate. Structural contingency theory, for instance, enjoys wide support in the organization-scientific community not because it is true but because it is empirically adequate: knowing the values of contingency variables such as size, task interdependence, and uncertainty, we can make satisfactorily accurate theoretical predictions about the structure of an organization (Donaldson, 2001). In a similar vein, theories are in research practice rejected not by demonstrating that they are false, but by showing that they are empirically inadequate, vague, ad hoc, or internally inconsistent (e.g., Cartwright, 1983).

The idealization strategy is supported by normative epistemology and methodology, it is exact, established and in a sense, objective. Even though the HD method as an idealization does not describe what the researcher has actually done, it can illuminate and make understandable arguments where theory has preceded empirical analysis (Kaplan, 1964). Inductive case study 
(Eisenhardt, 1989), in turn, illuminates arguments based on theory-generating multiple case study. Both approaches thus enable authors to reconstruct their research so that the audience will understand the warrants and their backing: idealizations provide a common language and play an important role in the "intellectual constitution of communities" (Zald, 1995: 477).

Potential challenges to the idealization strategy. The most appealing aspect of idealization is also its greatest weakness: as an abstraction it is an inadequate description of research practice. Because of the problem of induction, there is no general rule for selecting between alternative explanations. Consequently, applying idealization means that researchers are to abstract away all local standards they applied in their reasoning. HD, for instance, can indeed be interpreted as an invitation for researchers to sidestep altogether the selection between competing explanations. Inter-subjective idealizations of induction in a peculiar way "mystify" the entire process of theoretical explanation.

In inductive case research, we often encounter the claim that "theories emerge from data" (e.g., Brown \& Eisenhardt, 1997; Corley \& Gioia, 2004; Eisenhardt, 1989). This suggests that the data—not the researchers—guide the reasoning towards the correct explanation. While we may marvel at the idea of theoretical propositions objectively and impartially emerging from data by means of inter-subjective reasoning, many of us cannot stop wondering what the authors actually did and how they arrived at the specific theoretical interpretation. Were they really able to separate inference from explanation? Faced with the same evidence, would we really have arrived at the same explanation? Eisenhardt and Graebner (2007: 25) argued that "well-done theory building is surprisingly 'objective,' because its close adherence to the data keeps the researchers 'honest.' The data provide the discipline that mathematics does in formal analytical modeling.” This statement suggests that inductive case study researchers can in practice abstract 
away their own involvement in the reasoning process. Many organization scientists do not, however, believe this to be possible, and thus reject the idea of developing theory from data through inter-subjective reasoning. One of the main points of critique is that all declarations of objectivity aside, if we take an honest look at research practice, researchers' own creativity and ingenuity always shape the outcome of the reasoning process (Lipton, 2004).

The possibility of idealized inference can be viewed as problematic, because it ignores the role of the scientist as an active reasoner. Critics might thus not reject case study that relies on intersubjective induction, but they might ask: Is it not Kathleen Eisenhardt’s expertise, ingenuity and idiosyncratic abilities as a researcher, not some inter-subjective form of reasoning, that make her arguments compelling? Would we not benefit from a more reflexive account of how she chose to cope with the idiosyncrasies she encountered in her research? This point was indirectly raised in the debate following the publication of Eisenhardt's (1989) seminal paper on multiple case study. Dyer and Wilkins (1991) criticized Eisenhardt's approach by arguing that organization science needs "better stories instead of better constructs.” In-depth single case studies, Dyer and Wilkins argued, would likely lead to "better stories," because they would allow a more comprehensive exploration of both the empirical context studied as well as the subjective context of the researcher's reasoning process. Eisenhardt (1991) responded that we would arrive at better stories precisely through rigorous development of constructs. She maintained that good scientific stories must be based on robust constructs—inference first, then explanation.

The HD model is subject to similar critique of masking idiosyncrasy. While appeals to the HD model can constitute a powerful reasoning strategy, building arguments solely on such idealized methodology leaves out crucial aspects of reasoning associated with crossing the boundary between one's data and a theoretical conclusion. If in fact we never in practice derive hypotheses 
from theory deductively (Gorski, 2004; Hempel, 1965: 412), what is it that those of us who apply HD have really done? Most importantly, to what extent will our audiences need to and want to understand what we really did?

At the extreme, idealizations develop into simple heuristics that become completely detached from all methodological consideration. Various rules of thumb about statistical significance (e.g., the " $\mathrm{p}<.05$ ” rule), empirical adequacy (e.g., criteria for the $\mathrm{R}^{2}$-statistic in regression analysis), and adequate measurement reliability (e.g., the "Cronbach's alpha >.70" rule) are illustrative examples of idealizations gone awry. The .05 significance level has no methodological basis (Harlow, Mulaik, \& Steiger, 1997; Ziliak \& McCloskey, 2008); all criteria for the $\mathrm{R}^{2}$-statistic are arbitrary conventions (e.g., Kennedy, 2003); all universal rules about what constitutes adequate measurement reliability are oversimplifications of complex and context-dependent passages of text (Lance, Butts, \& Michels, 2006; Nunnally \& Bernstein, 1994). The common theme in all these examples is critique of idealizations based on arbitrary social conventions.

To be sure, nothing is more useful for facilitating science as a social activity than a simple, institutionalized operational definition of what constitutes, say, adequate measurement reliability or statistically significant association. These definitions enable us to move from grounds even to the most complex of claims in a deductively valid fashion. We must, however, acknowledge that the more our reasoning becomes detached from methodology and trade off methodological rigor for convenience, the more our scientific rhetoric transforms into its derogatory counterpart, "mere rhetoric," where methodology plays at best the role of an external referent of prestige. Deducing from ill-founded premises leads only to ill-founded conclusions. 


\section{Contextualization}

Contextualization embraces IBE and treats explanation and inference as inseparable, making inference in a manner of speaking contextualized, not abstracted or idealized. In contrast with idealization and appeal to inter-subjective reasoning, contextualization seeks to establish the contextual authenticity of reasoning. Specifically, reasoning is viewed as a context-dependent process, focused on arriving at what the researcher and the audience judge to be the best explanation for the data in light of the epistemic virtues embraced.

Context-dependence of reasoning can mean different things; we have identified three distinct forms. The first, subjective contextualization is based on the premise that all researchers have idiosyncratic backgrounds and knowledge bases, which are reflected in their reasoning style. Sometimes one's reasoning strategy is based expressly on a detailed description of one's reflexive thought process (Weick, 1989). The audience in turn will assess the justification of a particular inductive argument against this reflexive account, which has been narrated by an active voice in a particular style and genre (Golden-Biddle \& Locke, 1993). Proponents of subjective contextualization might indeed view scientific writing as "a particularly intimate form of autobiography” (Barney, 2005: 280). The contextual strategy shifts focus from knowledge to the practices of knowing (Cook \& Brown, 1999; Van de Ven \& Johnson, 2006). When the focus is not on what we know but how we come to know, warrant-seeking involves the examination of the authenticity of the researchers' accounts of data and their demonstration of critical thinking and evaluation of alternative explanations (Golden-Biddle \& Locke, 1993).

The second kind, empirical contextualization, is aimed at providing the reader with maximal access to the empirical context. By discussing telling examples and contextual detail, the author 
can establish a sense of empirical authenticity (Cook \& Brown, 1999; Golden-Biddle \& Locke, 1993; Van de Ven \& Johnson, 2006). This links back to subjective contextualization as well, because uniqueness is typically the researcher's own reconstruction. Van Maanen (1988: 73) noted that: "ethnographic writing of any kind... is dependent on an uncountable number of strategic choices and active constructions (e.g., what details to omit; how to summarize and present data; what voice to select; what quotations to use)." Ethnographers in particular have maintained that "thick description" is necessary in interpreting cultures and that uniqueness of context is to be favored over generalizability (Geertz, 1977), although the idea is by no means limited to ethnography or even qualitative research (e.g., Folger \& Turillo, 1999).

Empirical contextualization can be a particularly powerful tool in case research if the case organization is known to the audience. Burgelman's (1994) inferences and explanations in the case of Intel are in an important way based on the fact that it is specifically Intel that is being examined and that it was specifically Andy Grove (Burgelman, 1994: 42) who was the source of a specific insight. Boje’s (1995) and Van Maanen’s (1991) studies of Disney are other examples of empirical contextualization. Boje’s arguments, for instance, would be much less compelling, had his study been about an anonymous film studio and its powerful president, John Doe. Indeed, empirical contextualization was the strategy Boje (1995: 997) used in the opening sentence of his paper: "Who is better known, Jesus Christ or Mickey Mouse?"

It is important to distinguish between empirically contextualized reasoning and the more general notion of context specificity. It is always important to examine the boundary conditions of one's claims (e.g., Whetten, 1989); many of these conditions may be empirical. All empirical research takes place in one context or another, and the results are in an important way contextualized. In statistical research, for instance, the primary inference is made to an empirical context 
(=population), not theory. Further, operationalization of theoretical constructs can also be construed as a process of empirical contextualization. In contextualized reasoning, however, the empirical context becomes intertwined with the process by which grounds are linked to claims, and the author makes appeals to the context in justifying theoretical conclusions. Instead of defining or perhaps limiting the empirical scope of the argument, empirical contextualization uses the context as a warrant for a theoretical explanation. Such contextualization of one's reasoning is less common than the more general notion of contextualization of grounds and in particular, claims.

The third kind, theoretical contextualization, seeks warrants through establishing the relevance of claims with respect to a particular theory. To be sure, all organizational research, regardless of the reasoning strategy employed, is expected to contribute to a theoretical discourse. When theoretical contextualization in reasoning is used, however, theory plays an integral role in the reasoning process that produces the claim. Theoretical concerns, not just methodological principles, are used to justify a particular explanation over others. In contrast, those who apply idealization seek to contribute to theory as well, however, they do not allow theoretical explanations to interfere with the inference process. In idealization, inference is justified by demonstrating compliance with idealized inference principles either before (e.g., inductive case study) or after (e.g., HD) theory is invoked, not during the inference process.

When theoretical contextualization is used, the virtue driving the reasoning process is conservation and consolidation of a particular theory (Sklar, 1975). Showing that a specific interpretation of the data is linked to the concerns of a theoretical discourse is invoked as the warrant. Klein, Crawford and Alchian’s (1978) interpretation of the General Motors-Fisher Body merger as an instance of "transaction cost economics in action" is an excellent example of 
theoretical contextualization. Klein et al. in a sense "conserved” TCE as a theoretical discourse by demonstrating its utility in producing explanations of relevant empirical phenomena: GM's purchase of Fisher Body in 1926 (=grounds) could be understood as a strategic option to alleviate contractual hazards arising from uncertainty and opportunistic potential (=claim) (Klein et al., 1978: 308-310), or as Mahoney (2005: 137) put it, “vertical integration via financial ownership is persuasively explained in these property rights/transaction costs terms.” But how is it possible in 1978, fifty years after the fact, to draw a conclusion about opportunism when the researchers have neither directly nor indirectly observed it? It is precisely the TCE/property rights theory that warrants opportunism in the claim and makes the explanation not true but theoretically persuasive. TCE has thus become an integral part of the reasoning process and consequently, the reasoning process exhibits the key characteristics of IBE. Similar examples can be found in many organization-scientific discourses: institutional theorists draw conclusions about coercive mechanisms of isomorphism without actually observing coercive mechanisms empirically; contingency theorists write about the effects of complexity on organization structure, observing directly neither complexity nor the mechanisms through which complexity affects structure; innovation researchers draw conclusions about innovation without actually observing innovative activity; the list is endless. All examples make use of theory-conserving IBE in critical phases of the reasoning process.

Potential challenges to the contextualization strategy. Contextualization openly subscribes to context dependence, which leads to its most crucial weakness: the challenge of subjectivism. Within the contextualization strategy, explanations make sense only if we accept the underlying contextual idiosyncrasy, be it theoretical, empirical or researcher specific. But what is the basis 
for choosing a particular idiosyncrasy? Who will be willing to accept, and why, the interestingness of an explanation as a legitimate reason for its selection in scientific discourse?

This critique applies to all three forms of contextualization. In the case of theoretical contextualization, many critics of Klein et al.’s TCE interpretation of the GM-Fisher merger have simply denied the TCE warrant. Most notably, Coase (2006: 268) argued that Klein et al. were simply mistaken: “all parts of the tale that make up the 'classic example' of asset specificity leading to opportunistic behavior are wrong.” Interpreted using IBE terminology, Coase (2006: 268) was uncomfortable with theory conservation as a virtue guiding inference: "Facts are not like clay on a potter's wheel, that can be molded to produce the desired result. They constitute the immutable material that we have to accept.” The clay metaphor is similar to Glaser’s (1992) concern that researchers may "contaminate" their data. Coase clearly struggled with the idea that arguments to demonstrate the empirical power of TCE invoke the very same theory in the inferential process. The disagreement is one of epistemic values: Coase argued for truth and objectivity — the Spartan view—as the basis of epistemic values. Klein et al. in turn sided with the explanationist view and favored interestingness and conservativeness.

Critique of subjective contextualization is aptly illustrated in the recent debate in the Academy of Management Review over a new methodological approach that portrayed organization scientists as solvers of mysteries (Alvesson \& Kärreman, 2007). McKinley (2008: 542) criticized this new method by its lack of attention to replication, arguing that "mysteries can never be stabilized and generalized into objects worthy of sustained attention to organization studies scholars.” Alvesson and Kärreman (2008: 543) responded: "as advocates of a constructivist approach, the replication of studies is not something... that we find very important.” Instead of aiming at stability and generalizability, they sought to use phenomena to encourage "reflexivity and new lines of 
inquiry.” The notion of mystery clearly builds on the contextualization strategy: mysteries are mysteries constructed by a particular reflexive investigator in a particular context, and data are used to solve the mystery that intrigues the investigator. There are many ways to frame any given mystery (e.g., Simon, 1997: 126), and the choice is up to the investigator. The audience may or may not find this acceptable. McKinley in particular seemed to reject the premise, arguing for the idealized procedure of replication which would consolidate the factual basis of inferences before explanation can be pursued.

Finally, empirical contextualization may be challenged by questioning the generalizability and unbiasedness of the findings. The debate around deconstruction as a practice of interpreting organizations-as-texts is a good illustration of the challenges with empirical contextualization. To clarify, in deconstruction it is the specific text under scrutiny that is empirical and empirical contextualization is thus contextualization of this text. Deconstruction has produced radical arguments about both key texts within organization theory (Kilduff, 1993) as well as discourses within organizations (Boje, 1995; Martin, 1990). Deconstruction is characteristically a local practice, specific to the particular empirical text studied. Indeed, "successful deconstruction can open up a text's complexity using only the text's own resources... Deconstruction must follow the contours of the text itself” (Kilduff \& Kelemen, 2004: 261, 263). Organizational researchers experienced in deconstruction have emphasized that deconstruction, like any interpretation of a text, is open for reinterpretation and its results are never final (Derrida, 1976; Kilduff, 1993; Martin, 1990). Indeed, in her conclusion to one of the well-known deconstructions in organization science, Martin (1990: 355) remarked that "any deconstruction can itself be deconstructed.” This incompleteness leads to a crucial question: When do researchers stop deconstructing and how do they justify this so that they secure the necessary warrants? Using the 
uniqueness of one's empirical context—be it a text or some other form of empirical data—as the warrant is always subject to the critique that the findings are not general enough to warrant the attention of the scientific community.

\section{UNDERSTANDING AND IMPROVING ARGUMENTS THROUGH ENDOGENOUS AND EXOGENOUS DIALOGUE}

Our work as empirical scientists involves hard and strictly speaking, methodologically unbearable choices (McGrath et al., 1982). Both the author but in particular the audience must be respectful of the dilemma that incompleteness of inductive reasoning presents. Rejecting the HD model of reasoning because it fails to solve the problem of induction is acceptable in philosophical inquiry (Salmon, 1971) but unreasonable as a standard for evaluating empirical research. Similarly, demanding idealization when the author has used contextualization is inappropriate: calls to shift from one reasoning strategy to another have research policy not methodology at their foundation. Unless a journal has an editorial policy that explicitly favors one reasoning strategy over the other, all expressions of preference on part of the referee constitute nothing less than an act of academic violence.

To be sure, acknowledging the dilemma and respecting author's choices does not mean that we should never call into question any arguments. We all come across arguments where authors have simply failed in the application of any compelling reasoning strategy, and theoretical conclusions seem to appear out of thin air. In some cases we cannot understand what the argument is, or the argument appears so trite and self-evident that it fails to engage our intellect (Daft, 1995; Kilduff, 2007). This is of course unfortunate, but situations that are inequitable and 
disconcerting are ones where the audience not only rejects the choice of the author's reasoning strategy, but also thinks the rejection has a methodological basis.

Learning to live with the dilemma requires a new way of thinking about scientific debate that takes place between the author and the audience of an argument. Because of the incompleteness of induction, both authors and evaluators face the challenge of choosing between a number of competing explanations: Whom do I believe? Which strategy do I choose? If I face a number of conflicting reviews, how do I react without contradicting myself? In reviewing a manuscript, which standards should I adopt? The stakes could not be higher: it is our careers or those of our peers, not to mention the future careers of our students.

This paper is an invitation to developing mutual understanding through constructive dialogue. The incompleteness of the two strategies and their incommensurability means that any instance of such dialogue will potentially exhibit both a methodological and a political aspect. Whenever the audience accepts the author's reasoning strategy, focus shifts to methodology: Did the author use idealization in a clear and justified manner? Is the author using theoretical contextualization consistently with the theory in question? Does the audience find the use of subjective contextualization honest and appealing? Is the warrant based on empirical contextualization deemed authentic? These are methodological questions and we label this endogenous dialogue, dialogue within the reasoning strategy.

As soon as the critic begins to question the choice of the reasoning strategy or its tenets, or simply fails to acknowledge that we all as authors must make a choice, the dialogue turns to policy: Why did the author choose to separate inference from explanation? Why was TCE chosen as the basis of theoretical contextualization? Why is the author using methodologically 
incomplete reasoning in the first place? These challenges either question the basis of the author's reasoning strategy or simply ignore or deny the reasoning dilemma altogether. Unlike questions in endogenous dialogue, these questions have no methodologically founded answers, and the questions themselves are not methodological to boot. We label this exogenous dialogue, dialogue between or across reasoning strategies.

Both the authors and the audience must at all times be aware of the mode of dialogue: endogenous or exogenous, methodology or policy? The mode may not always be obvious, because the very same statement can be a methodological claim in one context but a policy claim in another, or methodological in the eyes of one side but political in the eyes of the other. A good example of this is the question of sample size. In a review of a quantitative study, the critic may raise the question of small sample size and argue, entirely on methodological grounds, that the author’s inference lacks statistical power (e.g., Mazen, Graf, Kellogg, \& Hemmasi, 1987). In a dialogue over a qualitative study, similar critique of the small sample size (e.g., Pratt, 2008) and lack of power is exogenous and expression of policy, because it indirectly rejects the author's reasoning strategy. In the following, we offer five normative guidelines to aid organization scientists develop their dialogic skills, both as authors and referees.

1. First endogenous, then exogenous dialogue. Despite the fact that "[d]oubting an assertion is the best way to find the error in it” (Elbow, 1973: 148), evaluation of an argument should always start with an invitation to endogenous dialogue: grant the author the choice of the reasoning strategy, first try to understand and only subsequently critically evaluate the arguments presented. Because of the incompleteness of inductive reasoning, finding an error in an argument where a conclusion is drawn from empirical data is always possible, hence, exogenous critique can always be summoned at will to decline a warrant. This is hardly a constructive way to start a 
dialogue. We must, therefore, not immediately reject Klein et al.’s (1978) interpretation of the GM-Fisher merger, because we do not accept theoretical contextualization as a reasoning strategy. In the absence of universal methodological criteria to decide which reasoning strategy is superior, those who wish to declare either Coase or Klein et al. the winner of the debate must do it exogenously, that is, on the basis of policy not methodology.

Exogenous dialogue is not without merit if carefully applied. It helps us understand the blind spots of the author's reasoning strategy and the potential alternative arguments and interpretations. In this sense, Coase’s critique of the Klein et al. interpretation served an important purpose. Exogenous dialogue does not, however, mean that the author be forced to adopt the alternative reasoning strategy to demonstrate impartiality, or that the critic declare the author to be mistaken; it merely calls for acknowledgment of the dilemma and its consequences.

Exogenous critique must also be understood as an invitation to dialogue. In quantitative research, for instance, authors often appeal upon challenge to the Popperian clause that theories are to be accepted only tentatively, pending falsification by further evidence. While this is true, such "offthe-shelf methodological disclaimers” are not fruitful material for dialogue. Constructive exogenous dialogue requires participants to move beyond scripted dialogue to explicitly weighing the strengths and the weaknesses of the argument. The goal of this dialogue is not to debate who is right and who is wrong; from a methodological point of view, both sides are wrong. The goal of exogenous dialogue should be jointly to illuminate alternative ways of interpreting data (e.g., Van Maanen, 1995: 140).

2. Understand theory-ladenness of reasoning. Most of us are familiar and comfortable with the idea of theory-ladenness of observation (e.g., Hanson, 1958; Kuhn, 1996; Sellars, 1956). But to 
what extent do we understand theory-ladenness of reasoning, which is central in theoretical contextualization in particular? Do we understand the epistemic virtues that the author has chosen to adopt in theoretical contextualization? Are we aware that the author has chosen not to separate inference from explanation? The last question in particular is important, because most of us are early in our careers taught to separate inference from explanation and view theoryindependent inference as a normative standard with supposedly a solid basis in methodology. In doctoral education, many methods seminars address inference and theory seminars explanation. At what point do we develop an understanding of the bridge between inference and explanation and most importantly, the decision not to separate the two? At what point do we recognize that our choice to separate inference from explanation has been political, not methodological?

Should for instance statistical methods be taught independently of theoretical explanation? Trying to understand statistical inference without simultaneously addressing explanation may be ill-advised, because it runs the risk of leading to over-emphasis on inference and rule-following (e.g., Ziliak \& McCloskey, 2008). Various statistical rules of thumb are the most troubling manifestation of this, and everyone who uses statistical inference must understand that there are scientists who are highly critical and frustrated about their use: "significance testing is surely the most bone-headedly misguided procedure ever institutionalized in the rote training of science students” (Rozeboom, 1997: 335). While significance testing is hardly going to disappear from organizational research, we must ask: Exactly how useful and credible are such highly generalized idealizations at the basis of an argument? Related questions relevant to qualitative research are: What is the best way to teach in particular those qualitative methods that do not separate inference from explanation? Can qualitative methods even be taught in isolation from 
the subject matter studied? All these questions are variations on a theme: How meaningful is it to separate inference from explanation?

\section{Understand objectivism and subjectivism in practical reasoning. The contextualization} strategy reveals important aspects about scientists as active reasoners. Understanding contextualization sheds further light on (1) Deetz's (1996: 194) claim that the idea of objectivity in research is more a "rhetorical move than a useful descriptive label," and (2) that contextualization does not mean that “anything goes” (Martin, 2005: 397) or the misconception that subjectivists allow themselves to "retrofit their data" to the preferred explanation (Wodak, 2004). On the first point, objectivity in reasoning is not fact but declaration and can critically be described as merely a rhetorical commitment to the normative. We must understand that although it is not immediately obvious, rejecting the idea of objectivity in reasoning is ultimately a statement of research policy, not methodology. If we reject objectivity because its application in research practice is methodologically incomplete, we have no choice but to reject subjectivity on the very same criterion. If we require one form of reasoning to solve the problem of induction, not holding all alternative forms of reasoning to the same standard is a strong expression of policy.

On the second point, contextualization means that subjectivist researchers, many of whom use the contextualization strategy, have simply chosen a basis different than idealization in their reasoning. This different basis is, however, just as committed to scientific rigor, only rigor of different variety. Indeed, various methodological accounts on reflexivity (Alvesson, 2003; Alvesson \& Sköldberg, 2000) have demonstrated that being suspicious of objectivity is not the same as being suspicious of scientific rigor. Commitment to contextualization must, despite its weaknesses and incommensurability with idealization, be not only tolerated but also understood. 
4. Do not reject idealization. Why do we reconstruct our research to comply with an idealized framework? Why do we not instead openly describe what we have done, and eliminate all references to methodological idealizations that are never followed in the first place? Those who answer the second question in the affirmative might suggest that contextualization is a superior strategy. This may seem appealing at first sight, but we must understand the consequences. Rejection of idealization would lead to rejection of the philosophy of science as the guide to organizational research, which in turn would constitute a redirection in research policy uncomfortable to many organization scientists. Abandoning idealization altogether would be a death blow to all possibilities of impartial testing of competing theoretical propositions on the classical epistemic virtues. It would further make the evaluation of contributions more difficult, because we would lose many of the schemas against which we now evaluate one another's arguments. Calls to abandon idealization always have and always will fall on deaf ears.

Supplanting idealization with contextualization would, however, also constitute a strong expression of policy. This is because contextualization too is based not on meticulous description of what the author has done, but indeed on a reconstruction of the inference process. Because of page restrictions, suggestions from reviewers, and other social conventions, a 20-page journal article never mirrors one’s research practice, it is but a reconstruction. Page restrictions aside, Lipton (2004) argued that our idiosyncratic reasoning processes are likely not observable even to ourselves, hence, they may be impossible to describe (see also Kuhn, 1996: 44). Polanyi's (1958: 49) remarks on tacit knowledge may thus apply not only to activities such as face recognition, swimming, and riding the bicycle, but also to scientific reasoning: "[T]he aim of a skilful performance is achieved by the observance of a set of rules which are not known as such to the person following them.” Convincing an audience, if anything, constitutes a skilful performance. 
Scientists like decision-makers are boundedly rational, hence, reconstruction can never be eliminated. The relevant questions to ask are: What is the basis of reconstruction? Which aspects of one's research are more important to reconstruct than others in trying to convince an audience (Van Maanen, 1988)? The contextualist strategy takes this challenge more seriously than idealization, but does not offer answers that are unambiguously superior. If it did, no-one would use idealization, because it would be inferior as a reasoning strategy.

Acknowledging the limits of idealization more explicitly is a more realistic prescription. Those of us who believe in the possibility of the scientific method for organization science do not acknowledge the enduring dilemma that the problem of induction presents. Researchers who think their reasoning practices are de facto methodologically complete are in denial or unaware of the blind spot in their reasoning strategy.

5. Make a choice, defend it. As a general rule, authors should base their reasoning on either contextualization or idealization: either separate inference and explanation or treat the two as one. If the audience accepts the choice, warrant-granting becomes a matter of endogenous critique and will likely lead to fruitful dialogue. But what is a researcher to do when faced with exogenous critique and when the choice is challenged? For instance, "[m]any reviewers seem to evaluate [interpretive] research with positivistic criteria” (Pratt, 2008: 491).

Our primary recommendation is directed at those who evaluate arguments and choose to present exogenous critique. Unless there is an explicit editorial policy that favors a specific reasoning strategy, critics must place their words of exogenous critique carefully. There is no methodological basis for challenging the author's choice. Absent any explicit policy, the task of the evaluator should be to determine whether the strategy the author has chosen is credibly 
executed. Authors cannot simply shift from using one strategy to another upon challenge, because this might mean that they have to pretend that they have separated inference and explanation from one another when in fact they have treated the two as one.

All of us want to get our arguments published and if challenged by a reviewer or the editor, may feel compelled to adopt the standards of the other reasoning strategy to satisfy exogenous critique. While we see little harm in, say, a qualitative researcher admitting to small sample size as a "shortcoming" to satisfy a particular reviewer. In this multi-paradigmatic field of ours, conflicting demands can sometimes only be satisfied by hypocritical writing. This is a slippery slope, however. Adopting two sets of standards, relying on idealization in one part of the argument and contextualization in another, is likely to lead to contradiction. Our recommendation is that authors choose one strategy and ensure their reasoning is consistent with that strategy. Those who evaluate the argument should in turn accept the author's choice of reasoning. We hope we have established in this paper that such acceptance is justified, equitable, and fruitful.

\section{Conclusion}

Warrants for arguments are always sought in an environment beset with dilemmas and unavoidably methodological incompleteness of claims (McGrath, 1982). Toward the end of continuously developing our reasoning skills both as authors and as evaluators, we have introduced a new level of analysis to scientific dialogue and debate by presenting two reasoning strategies as practical responses to these dilemmas. Further, the dialogue in which the merits of the argument are weighed should not—cannot—be an attempt to determine the veracity of the claim, but rather, a cooperative attempt at illuminating the argument. We find great wisdom in 
Van Maanen's (1995) call for less debate and more dialogue. Brought to the context of reasoning strategies and evaluation of claims, exogenous dialogue that focuses on debate can easily lead to automatic gainsay of arguments based on policy and preference. Such gainsay is neither dialogue nor debate, it is little more than two sides to an argument taking turns talking past one another.

We take exception to Laudan’s (1981: 153) suggestion that “[d]ialectical confrontations are essential to the growth and improvement of scientific knowledge; like nature, science is red in tooth and claw.” Because of the problem of induction, we need to seek balance between confrontation and dialogue. There is a time and a place for confrontation and hopefully, our distinction of endogenous and exogenous dialogue at the reasoning level of analysis helps us understand the right time for dialectical confrontation in organization-scientific inquiry. Dialectical confrontation should be restricted primarily to endogenous dialogue, where both the author and the audience agree to play by the rules of the same reasoning strategy. Obviously, policy confrontations serve an important function in our profession as well, but the assessment of the credibility of an argument presented by an author in a manuscript or conference presentation is not the time for such confrontation. Yet, Pratt (2008) observed that such confrontations indeed continually take place in these settings.

In closing, we wish to invoke a sentiment of responsibility in our reasoning. The ultimate responsibility for an argument does not lie with idealization, contextualization, social conventions, external referents, or the audience. While scientific reasoning is, as Toulmin construed, a collective effort, full responsibility of the claim must remain squarely with the author. The acceptance of an argument into the body of knowledge is a collective accomplishment, to be sure, but the only legacy being built and the only reputation at stake is that of the author's. We cannot think of a better incentive for organizational researchers to 
become not just authors but also genuine critics of both the contents of their claims as well as the processes that produce them. 


\section{REFERENCES}

Alvesson, M. 2003. Beyond neopositivists, romantics, and localists: A reflexive approach to interviews in organizational research. Academy of Management Review, 28: 13-33.

Alvesson, M., \& Kärreman, D. 2007. Constructing mystery: Empirical matters in theory development. Academy of Management Review, 32: 1265-1281.

Alvesson, M., \& Kärreman, D. 2008. On the social nature of explicating mystery construction in theory development: A response to McKinley. Academy of Management Review, 32: 543-545.

Alvesson, M., \& Sköldberg, K. 2000. Reflexive Methodology, New Vistas for Qualitative Research. London: Sage Publications.

Astley, W. G. 1985. Administrative science as socially constructed truth. Administrative Science Quarterly, 30: 497-513.

Barney, J. B. 2005. Where does inequality come from? The personal and intellectual roots of resource-based theory. In K. G. Smith, \& M. A. Hitt (Eds.), Great Minds in Management: The Process of Theory Development: 280-303.

Ben-Menahem, Y. 2001. Convention: Poincaré and some of his critics. British Journal for the Philosophy of Science, 52: 471-514.

Boje, D. M. 1995. Stories of the storytelling organization: A postmodern analysis of Disney as 'Tamara-Land'. Academy of Management Journal, 38: 997-1035.

Brown, S. L., \& Eisenhardt, K. M. 1997. The art of continuous change: Linking complexity theory and time-paced evolution in relentlessly shifting organizations. Administrative Science Quarterly, 42: 1-34. 
Burgelman, R. A. 1994. Fading memories: A process theory of strategic business exit in dynamic environments. Administrative Science Quarterly, 39: 24-56.

Carnap, R. 1950. Logical Foundations of Probability. Chicago, IL: University of Chicago Press.

Carter, R., \& Hodgson, G. M. 2006. The impact of empirical tests of transaction cost economics on the debate on the nature of the firm. Strategic Management Journal, 27: 461-476.

Cartwright, N. 1983. How the Laws of Physics Lie. New York: Clarendon Press.

Coase, R. H. 2006. The conduct of economics: The example of Fisher Body and General Motors. Journal of Economics \& Management Strategy, 15: 255-278.

Cook, S. D. N., \& Brown, J. S. 1999. Bridging epistemologies: The generative dance between organizational knowledge and organizational knowing. Organization Science, 10: 381400.

Corley, K. G., \& Gioia, D. A. 2004. Identity ambiguity and change in the wake of a corporate spin-off. Administrative Science Quarterly, 49: 173-208.

Daft, R. L. 1995. Why I recommended that your manuscript be rejected and what you can do about it. In P. Frost, \& L. L. Cummings (Eds.), Publishing in the Organizational Sciences, 2nd ed.: 164-182. Homewood, IL: Irwin.

Deetz, S. 1996. Describing differences in approaches to organization science: Rethinking Burrell and Morgan and their legacy. Organization Science, 7: 191-205.

Derrida, J. 1976. Of Grammatology. Baltimore: Johns Hopkins University Press.

Donaldson, L. 2001. The Contingency Theory of Organizations. Thousand Oaks, CA: Sage Publications.

Dyer, W. G., Jr., \& Wilkins, A. 1991. Better stories, not better constructs: A rejoinder to Eisenhardt. Academy of Management Review, 16: 613-619. 
Eisenhardt, K. M. 1989. Building theories from case study research. Academy of Management Review, 14: 532-550.

Eisenhardt, K. M. 1991. Better stories and better constructs: The case for rigor and comparative logic. Academy of Management Review, 16: 620-627.

Eisenhardt, K. M., \& Graebner, M. E. 2007. Theory building from cases: Opportunities and challenges. Academy of Management Journal, 50: 25-32.

Elbow, P. 1973. Writing Without Teachers. Oxford: Oxford University Press.

Folger, R., \& Turillo, C. J. 1999. Theorizing as the thickness of thin abstraction. Academy of Management Review, 24: 742-758.

Frigg, R., \& Hartmann, S. 2006. Models in science. In E. N. Zalta (Ed.), The Stanford Encyclopedia of Philosophy. http://plato.stanford.edu/archives/win2006/entries/modelsscience/.

Geertz, C. 1977. Interpretation of Cultures. New York: Basic Books.

Glaser, B. G. 1992. Basics of Grounded Theory Analysis. Mill Valley, CA: Sociology Press.

Glaser, B. G., \& Strauss, A. L. 1967. The Discovery of Grounded Theory: Strategies for Qualitative Research. Hawthorne, NY: Aldine de Gruyter.

Golden-Biddle, K., \& Locke, K. 1993. Appealing work: An investigation of how ethnographic texts convince. Organization Science, 4: 595-616.

Goodman, N. 1954. Fact, Fiction, and Forecast. Cambridge, MA: Harvard University Press.

Gorski, P. S. 2004. The poverty of deductivism: A constructive realist model of sociological explanation. Sociological Methodology, 34: 1-33.

Hanson, N. R. 1958. The logic of discovery. Journal of Philosophy, 55: 1073-1089. 
Harlow, L. L., Mulaik, S. A., \& Steiger, J. H. (Eds.). 1997. What If There Were No Significance Tests? Mahwah, N.J.: Lawrence Erlbaum Associates.

Harman, G. H. 1965. The inference to the best explanation. Philosophical Review, 74: 88-95.

Hempel, C. G. 1965. Aspects of Scientific Explanation and Other Essays in the Philosophy of Science. New York: Free Press.

Hume, D. 1969. A Treatise of Human Nature. London: Penguin Classics.

Josephson, J. R., \& Josephson, S. G. (Eds.). 1996. Abductive Inference: Computation, Philosophy, Technology: Cambridge University Press.

Kaplan, A. 1964. The Conduct of Inquiry. San Francisco: Chandler Publishing Company.

Kennedy, P. 2003. A Guide to Econometrics (5th ed.). Cambridge, MA: The MIT Press.

Kilduff, M. 1993. Deconstructing organizations. Academy of Management Review, 18: 13-31.

Kilduff, M. 2007. Editor's comments: The top ten reasons why your paper might not be sent out for review. Academy of Management Review, 32: 700-702.

Kilduff, M., \& Kelemen, M. 2004. Deconstructing discourse. In D. Grant, C. Hardy, C. Oswick, \& L. Putnam (Eds.), The Sage Handbook of Organizational Discourse. London: Sage Publications.

Klein, B., Crawford, R. G., \& Alchian, A. 1978. Vertical integration, appropriable rents, and the competitive contracting process. Journal of Law and Economics, 21: 297-326.

Kuhn, T. S. 1996. The Structure of Scientific Revolutions (3rd ed.). Chicago, IL: The University of Chicago Press.

Lance, C. E., Butts, M. M., \& Michels, L. C. 2006. The sources of four commonly reported cutoff criteria: What did they really say? Organizational Research Methods, 9: 202-220. 
Langley, A. 1999. Strategies for theorizing from process data. Academy of Management Review, 24: 691-710.

Laudan, L. 1981. A problem-solving approach to scientific progress. In I. Hacking (Ed.), Scientific Revolutions. Oxford: Oxford University Press.

Lipton, P. 2004. Inference to the Best Explanation. London: Routledge.

Locke, K. 1996. Rewriting the discovery of grounded theory after 25 years? Journal of Management Inquiry, 5: 239-245.

Locke, K., \& Golden-Biddle, K. 1997. Constructing opportunities for contribution: Structuring intertextual coherence and "problematizing" in organizational studies. Academy of Management Journal, 40: 1023-1062.

Locke, K., Golden-Biddle, K., \& Feldman, M. 2008. Making doubt generative: Rethinking the role of doubt in the research process. Organization Science, forthcoming.

Lycan, W. G. 1988. Judgment and Justification. Cambridge: Cambridge University Press.

Lycan, W. G. 1998. Theoretical (epistemic) value. In E. Craig (Ed.), Routledge Encyclopedia of Philosophy: 340-343. London: Routledge.

Maher, P. 1998. Inductive inference. In E. Craig (Ed.), Routledge Encyclopedia of Philosophy: 755-759. London: Routledge.

Mahoney, J. T. 2005. Economic Foundations of Strategy. Thousand Oaks, CA: Sage.

Martin, J. 1990. Deconstructing organizational taboos: The suppression of gender conflict in organizations. Organization Science, 1: 339-359.

Martin, J. 2005. Metatheoretical controversies in studying organizational culture. In H. Tsoukas, \& C. Knudsen (Eds.), The Oxford Handbook of Organization Theory: 392-419. Oxford: Oxford University Press. 
Mazen, A. M., Graf, L. A., Kellogg, C. E., \& Hemmasi, M. 1987. Statistical power in contemporary management research. Academy of Management Journal, 30: 369-380.

McGrath, J., Martin, J., \& Kulka, J. 1982. Judgment Calls in Research. Beverly Hills, CA: Sage Publications.

McGrath, J. E. 1982. Dilemmatics: The study of research choices and dilemmas. In J. E. McGrath, J. Martin, \& R. A. Kulka (Eds.), Judgment Calls in Research: 69-102. Beverly Hills, CA: Sage Publications.

McKelvey, B. 1997. Quasi-natural organization science. Organization Science, 8: 352-380.

McKelvey, B. 2002. Model-centered organization science epistemology. In J. A. C. Baum (Ed.), The Blackwell Companion to Organizations: 752-780. Oxford: Blackwell Publishing.

McKinley, W. 2008. The mystery about mysteries: A commentary on Alvesson and Kärreman. Academy of Management Review, 33: 541-543.

Moldoveanu, M. C., \& Baum, J. A. C. 2002. Contemporary debates in organizational epistemology. In J. A. C. Baum (Ed.), The Blackwell Companion to Organizations: 733751. Malden, MA: Blackwell Publishing.

Nagel, E. 1965. Induction and its justification. In E. Nagel, \& R. B. Brandt (Eds.), Meaning and Knowledge. Systematic Readings in Epistemology. New York: Harcourt, Brace \& World.

Niiniluoto, I. 1999. Defending abduction. Philosophy of Science, 66: S436-S451.

Nunnally, J. C., \& Bernstein, I. H. 1994. Psychometric Theory (3rd ed.). New York: McGrawHill.

Oliver, C. 1991. Strategic responses to institutional processes. Academy of Management Review, 16: 145-179. 
Peirce, C. S. 1878. Deduction, induction, and hypothesis. Popular Science Monthly, 13: 470482.

Pfeffer, J. 1993. Barriers to the advance of organizational science: Paradigm development as a dependent variable. Academy of Management Review, 18: 599-620.

Polanyi, M. 1958. Personal Knowledge: Towards a Post-Critical Philosophy. Chicago: University of Chicago Press.

Popper, K. R. 1959. The Logic of Scientific Discovery. London: Hutchinson \& Co.

Pratt, M. G. 2008. Tensions in evaluating and publishing qualitative research in top-tier North American journals. Organizational Research Methods, 11: 481-509.

Quine, W. V. 1951. Main trends in recent philosophy: Two dogmas of empiricism. Philosophical Review, 60: 20-43.

Quine, W. V., \& Ullian, J. S. 1970. The Web of Belief. New York: Random House.

Rozeboom, W. W. 1997. Good science is abductive, not hypothetico-deductive. In L. L. Harlow, S. A. Mulaik, \& J. H. Steiger (Eds.), What If There Were No Significance Tests?: 335391. Mahwah, N.J.: Lawrence Erlbaum Associates.

Salmon, W. C. 1966. The Foundations of Scientific Inference. Pittsburgh, PA: University of Pittsburgh Press.

Salmon, W. C. 1971. Statistical Explanation and Statistical Relevance. Pittsburgh, PA: University of Pittsburgh Press.

Santos, F. M., \& Eisenhardt, K. M. 2005. Organizational boundaries and theories of organization. Organization Science, 16: 491-508. 
Sellars, W. 1956. Empiricism and the philosophy of mind. In H. Feigl, \& M. Scriven (Eds.), Minnesota Studies in the Philosophy of Science, Volume 1: 253-329. Minneapolis: University of Minnesota Press.

Simon, H. A. 1997. Administrative Behavior (4th ed.). New York: Macmillan.

Sklar, L. 1975. Methodological conservatism. Philosophical Review, 84: 374-400.

Spedding, J., Ellis, R. L., \& Heath, D. D. (Eds.). 1901. The Works of Francis Bacon, Vol. IV. London: Routledge \& Sons.

Starbuck, W. H. 2006. The Production of Knowledge. New York: Oxford University Press.

Strauss, A. 1987. Qualitative Analysis for Social Scientists. Cambridge: Cambridge University Press.

Strauss, A., \& Corbin, J. 1990. Basics of Qualitative Research: Grounded Theory Procedures and Techniques. Newbury Park, CA: Sage Publications.

Toulmin, S. E. 2003. The Uses of Argument (Updated ed.). Cambridge: Cambridge University Press.

Van de Ven, A. H., \& Johnson, P. E. 2006. Knowledge for theory and practice. Academy of Management Review, 31: 802-821.

van Fraassen, B. C. 1980. The Scientific Image. Oxford: Clarendon Press.

Van Maanen, J. 1988. Tales of the Field: On Writing Ethnography. Chicago: Chicago University Press.

Van Maanen, J. 1991. The smile factory: Work at Disneyland. In P. J. Frost, L. F. Moore, M. R. Louis, \& C. C. Lundberg (Eds.), Reframing Organizational Culture. London: Sage. Van Maanen, J. 1995. Style as theory. Organization Science, 6: 133-143. 
Weick, K. E. 1989. Theory construction as disciplined imagination. Academy of Management Review, 14: 516-531.

Whetten, D. A. 1989. What constitutes a theoretical contribution? Academy of Management Review, 14: 490-495.

Whewell, W. 1840. The Philosophy of the Inductive Sciences, Founded Upon their History. London: John W. Parker and Son.

Williamson, O. E. 1985. The Economic Institutions of Capitalism. New York: Free Press.

Wodak, R. 2004. Critical discourse analysis. In C. Seale, G. Gobo, \& J. F. Gubrium (Eds.), Qualitative Research Practice: 197-213. London: Sage Publications.

Zald, M. 1995. Progress and cumulation in the human sciences after the fall. Sociological Forum, 10: 455-479.

Ziliak, S., \& McCloskey, D. 2008. The Cult of Statistical Significance: How the Standard Error Costs Us Jobs, Justice, and Lives. Ann Arbor, MI: University of Michigan Press. 


\section{FIGURE 1}

Practical reasoning, inference and explanation (adapted from Toulmin, 2003)

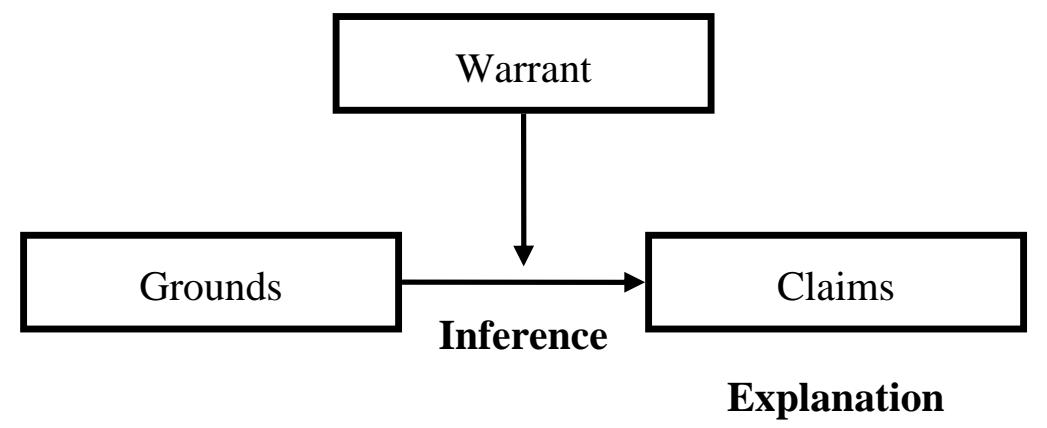


TABLE 1

Two strategic responses to the reasoning dilemma

\begin{tabular}{|c|c|c|}
\hline Strategy & Idealization & Contextualization \\
\hline $\begin{array}{l}\text { Characteristic } \\
\text { form of } \\
\text { inference }\end{array}$ & $\begin{array}{l}\text { Primarily induction (eliminative, } \\
\text { enumerative), but also deduction }\end{array}$ & $\begin{array}{l}\text { Inference to the best explanation } \\
\text { (abduction) }\end{array}$ \\
\hline $\begin{array}{l}\text { Inference and } \\
\text { explanation }\end{array}$ & $\begin{array}{l}\text { Separate activities: explanation } \\
\text { follows after inference has been } \\
\text { assessed }\end{array}$ & Intertwined, assessed simultaneously \\
\hline $\begin{array}{l}\text { Epistemic } \\
\text { virtue }\end{array}$ & $\begin{array}{l}\text { The Spartan view; Empirical } \\
\text { adequacy }\end{array}$ & $\begin{array}{l}\text { The explanationist view; Simplicity, } \\
\text { plausibility, interestingness, novelty }\end{array}$ \\
\hline $\begin{array}{l}\text { Backing for } \\
\text { warrants }\end{array}$ & $\begin{array}{l}\text { Compliance with methodological } \\
\text { idealizations }\end{array}$ & $\begin{array}{l}\text { Making contextualized inference } \\
\text { transparent; Demonstrating empirical } \\
\text { authenticity; Conservation of theories }\end{array}$ \\
\hline $\begin{array}{l}\text { Argumentation } \\
\text { strengths }\end{array}$ & $\begin{array}{l}\text { Explicit and established rules and } \\
\text { procedures; Generalizable results }\end{array}$ & $\begin{array}{l}\text { Transparent, openly partial to the } \\
\text { explanation; Authentic to data and } \\
\text { the research process }\end{array}$ \\
\hline $\begin{array}{l}\text { Challenges in } \\
\text { appealing for } \\
\text { warrants }\end{array}$ & $\begin{array}{l}\text { Neither necessary nor sufficient to } \\
\text { describe research practice; } \\
\text { Idiosyncrasies of data and } \\
\text { reasoning may appear concealed }\end{array}$ & $\begin{array}{l}\text { Unpredictability due to a lack of } \\
\text { methodological consensus; } \\
\text { Applicability of findings; The } \\
\text { challenge of subjectivism }\end{array}$ \\
\hline
\end{tabular}




\section{APPENDIX: GLOSSARY OF REASONING TERMS}

Abduction. American pragmatist philosopher Charles Peirce (e.g., 1878) argued that our reasoning in seeking explanations follows a distinct form of reasoning he labeled abduction, the general form of which is as follows (e.g., Niiniluoto, 1999): (1) the surprising fact C is observed;

(2) but if A were true, C would be a matter of course; (3) hence, there is reason to suspect that A is true. Abduction is distinct from both deduction and induction, and is logically the weakest form of reasoning; indeed, it falls prey to the fallacy of affirming the consequent. This aside, the use of abductive reasoning in research practice is just as common as deduction and induction (Josephson \& Josephson, 1996; Niiniluoto, 1999).

Deduction. A form of reasoning where a conclusion is derived logically from a set of premises. The conclusion is thus merely a restatement of the premises and as such does not contain any new knowledge. A conclusion based on deduction is true whenever all premises are true. The downside of deduction is that if any one premise is false, so is the conclusion.

Hypothetico-deductive research design. As a general label, HD refers to research where theory precedes empirical analysis and where observable hypotheses are derived from propositional theory and tested with empirical data. In its original, narrow definition (Hempel, 1965; Whewell, 1840), HD required hypotheses to be derived from theory in a deductive and thus analytically valid fashion, and to be tested using a controlled experiment and replication. From the point of view of both epistemology and theoretical explanation, HD has been shown to be highly problematic (Salmon, 1971).

Induction. Inductive reasoning is one of the primary forms of reasoning both in everyday life and scientific practice. It is an ampliative form of reasoning in that the conclusion is more than a 
restatement of the premises. The epistemological problem of induction is the fact that there is always a logical gap between the premises and the conclusions of an inductive argument (Hume, 1969). Unlike deduction, there are many variants of inductive reasoning (see below).

Induction, enumerative and eliminative. In its classical form, induction is simply an enumeration, a one-step empirical generalization based on multiple observations. After a certain number of instances compliant with a rule have been observed, the rule is judged to be supported by evidence (“all ravens are black”). Predating developments in enumerative induction within statistical theory, Francis Bacon developed in the early 1600s a more elaborate, eliminative (a.k.a. "Baconian") form of induction. Bacon argued that induction cannot proceed in a single step from observation to generalization. Instead, a number of intermediate hypotheses are formed, which are then replaced by more general ones as the induction progresses. Bacon is known for calling for research that begins with "pure" observation, uncontaminated by previous experience or predisposition. Observation is followed by tabulation of data and ultimately, generalization (e.g., Spedding, Ellis, \& Heath, 1901).

Inference vs. explanation. Inference covers the primarily inductive steps we take to generalize our empirical findings. Theoretical explanation covers the steps we take to formulate the findings in a theoretical language; in contrast with inference, there is no agreement on the exact forms of reasoning used in the explanation phase. Those who rely on inter-subjective forms of inductive inference tend to separate inference from explanation. In IBE and abduction in contrast, explanation becomes part of the inferential process. The HD method is perhaps the best illustration of the idea that engaging in inference and constructing an explanation are two distinct activities. 
Inference to the best explanation (IBE). The abductive process of reasoning that takes place when researchers compare potential theoretical explanations of a phenomenon is known as inference to the best explanation (IBE) (see Lipton, 2004, for a contemporary review). In IBE, the researcher selects the "best" out of a short list of plausible explanations based on considerations of epistemic virtues such as simplicity or novelty. IBE can be adopted by realists and anti-realists alike, but its origins are in realist philosophy (e.g., Harman, 1965).

Reasoning, subjective vs. inter-subjective. In inter-subjective reasoning, the role of the reasoner is ancillary and can be abstracted away: two researchers engaging in inter-subjective reasoning of the same data will (by assumption) arrive at the same conclusion. Deduction, eliminative induction and enumerative induction are inter-subjective forms of reasoning. Enumerative and eliminative views of induction suggest that when we look at evidence, we should "all see the same thing" in terms of arriving at the same generalization. In subjective reasoning, the researcher invokes contextualization—subjective, empirical or theoretical—in the inferential process.

Enumerative and eliminative induction are sometimes dubbed mechanistic forms of induction, because of their a priori structure: induction is akin to a machine that produces objective generalizations by following a sequence of pre-determined steps. Mechanistic induction holds that if the inductive procedure is followed correctly, the results are in a sense inevitable. 


\section{AUTHOR BIOGRAPHIES}

Mikko Ketokivi (mikko@ketokivi.fi) is a senior lecturer of management at Aalto University in Helsinki, Finland, and a visiting professor at University of Lausanne, Switzerland. His research interests include organization design, organizational integration, goal setting, operations management, and quantitative research methods.

Saku Mantere (saku.mantere@hanken.fi) is a professor (acting) of management and organization at Hanken School of Economics in Helsinki, Finland and affiliate professor at Rouen Business School, France. His research interests include strategy as practice, strategy process issues such as strategic change, organizational discourse, and qualitative research methods. 